\title{
One-handed helical double stranded polybisnorbornenes $\dagger$
}

\author{
Hui-Chun Yang, ${ }^{a}$ Sherng-Long Lee, ${ }^{a}$ Chun-hsien Chen, ${ }^{* a}$ Nai-Ti Lin, ${ }^{a}$ Hsiao-Ching Yang, ${ }^{b}$ \\ Bih-Yaw Jin $^{a}$ and Tien-Yau Luh*a
}

Received (in Cambridge, UK) 22nd August 2008, Accepted 18th September 2008

First published as an Advance Article on the web 16th October 2008

DOI: $10.1039 / b 814672 a$

Helical double stranded polymers incorporated with a covalently bound chiral ferrocene linker are synthesised and characterized by CD spectra and STM images and molecular dynamics simulations.

There have been ever burgeoning interests in artificial double stranded oligomers, polymers as well as supramolecular systems to mimic DNA chemistry. ${ }^{1-7}$ Chelation to metal ions, ${ }^{1}$ complexation through hydrogen-bonding, ${ }^{2} \pi-\pi$ stacking, ${ }^{3}$ or inclusion complexes ${ }^{4}$ are typical strategies for the construction of the helical double stranded oligomers. Ladder-like organic polymers with two strands connected by covalent, dative or ionic bonds have been briefly explored..$^{5-7}$ Only a handful of double stranded polymers has been identified unambiguously to be helical. ${ }^{1 j, 7,8}$ Stereoselective controls of the chirality of polymers leading to one-handed helical morphology can readily be achieved by incorporating a chiral auxiliary. Cooperative phenomena with an amplification of chirality have been shown to offer a powerful platform for the formation of helical polymers or supramolecules of single chirality. ${ }^{9}$ We recently reported the synthesis and characterisation of a double stranded bisnorbornene polymer 1 by ring opening metathesis polymerisation (ROMP) ${ }^{10}$ of the corresponding monomer $2 .{ }^{7}$ The characteristics of $\mathbf{1}$ includes a rapid equilibrium among helical, supercoil and ladder conformations. Preliminary molecular dynamics-molecular mechanics calculations suggest that the helical conformation in $\mathbf{1}$ might be more strained than the supercoil and ladder structures. The spacing between each monomeric unit in $\mathbf{1}$ is about $5.5 \AA^{7}$. $^{7}$ ectrochemical oxidation of $\mathbf{1}$ and related polymers suggested that all neighbouring monomeric units in these polymers may strongly interact with each other. ${ }^{11}$ It is envisaged that incorporation of substituent(s) onto the covalently bound ferrocene linker in $\mathbf{1}$ may lead to a conformational change so that the morphology of the polymers may be defined due to cooperative interactions between neighbouring monomeric units. Indeed, we recently found that unsymmetrical double stranded polymer $\mathbf{3}$, where the two polymeric strands are complimentary to each other, has a ladder-like structure, neither a helical nor supercoil structure being observed. ${ }^{6}$ Rational design and synthesis of double stranded polymers or supramolecular systems with predictable helicity remain to be a challenge. ${ }^{12}$ In this paper,

${ }^{a}$ Department of Chemistry, National Taiwan University, Taipei,

Taiwan 106.E-mail: tyluh@ntu.edu.tw; chhchen@ntu.edu.tw;

Fax: + 886223644971

${ }^{b}$ Department of Chemistry, Fu Jen Catholic University, Hsinchuang,

Taipie, Taiwan 242

$\dagger$ Electronic supplementary information (ESI) available: [DETAILS].

See DOI: $10.1039 / \mathrm{b} 814672 \mathrm{a}$

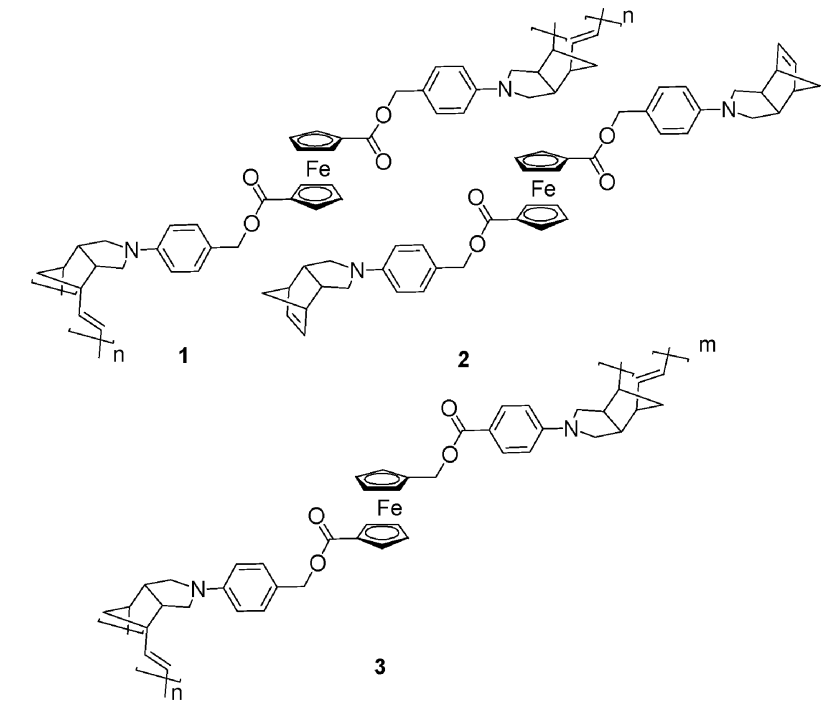

In our previous work, we used an ester linkage to connect the ferrocene-carboxylic acid moiety to the 4-aminobenzyl group to construct the double stranded bis-polynorbornene 1. It is noteworthy that the 4-aminobenzyl ester is very labile towards nucleophiles $^{13}$ so that the double stranded $\mathbf{1}$ can be easily transformed into two equivalents of the corresponding single stranded polymer. ${ }^{7}$ In order to increase the stability of the double stranded polymer, we swapped the ester group by coupling aminobenzoic acid with ferrocene-methanol derivatives 4 . Optically active diols 4 were prepared according to literature procedures. ${ }^{14}$ Reactions of acid chloride $\mathbf{5 b}$ with $\mathbf{4}$ afforded the corresponding monomeric bisnorbornene derivative 6 (eqn (1), $[\alpha]_{\mathrm{D}}{ }^{25}$ in $\mathrm{CHCl}_{3}$ (c $0.01 \mathrm{~g} \mathrm{~mL}^{-1}$ ): $R, R-\mathbf{- 6 a}-124.2, \quad S, S-\mathbf{6 a}+123.2, \quad R, R-\mathbf{- 6} \mathbf{b}$ $-37.0, S, S-6 \mathbf{b}+39.0)+\uparrow$ ROMP of $\mathbf{6}$ with Grubbs I catalyst afforded the corresponding double stranded polymers 7 (eqn (1), $M_{n}$ (PDI): $R, R-7 \mathbf{a} 16300$ (1.4), S,S-7a 17500 (1.5), $R, R$-7b 16300 (1.4), $S, S-7 \mathbf{b} 15000(1.3)) \cdot \dagger$ The ${ }^{13} \mathrm{C}$ NMR spectra of $\mathbf{6}$ and 7 are compared in Fig. 1. It is noteworthy that the olefinic carbons in 6 at $\delta 135 \mathrm{ppm}$ shifted to $c a . \delta 132 \mathrm{ppm}$ as a shoulder in 7 and the weak broad signals at $c a . \delta 37 \mathrm{ppm}$ were characteristic of the absorption of $\mathrm{C}_{7}$ in $7 .{ }^{6,7}$ All other peaks for 7 matched nicely those for $\mathbf{6}$. Hydrolysis of $\mathbf{7 b}$ gave $\mathbf{8 b}$ and the corresponding isotactic single stranded polymer $\mathbf{9}$ which was converted into a methyl ester 10 (eqn (2), $M_{n}$ (PDI): 5500 (1.2)). ${ }^{6,15}$ These results were consistent with the double stranded structure for 7 . 


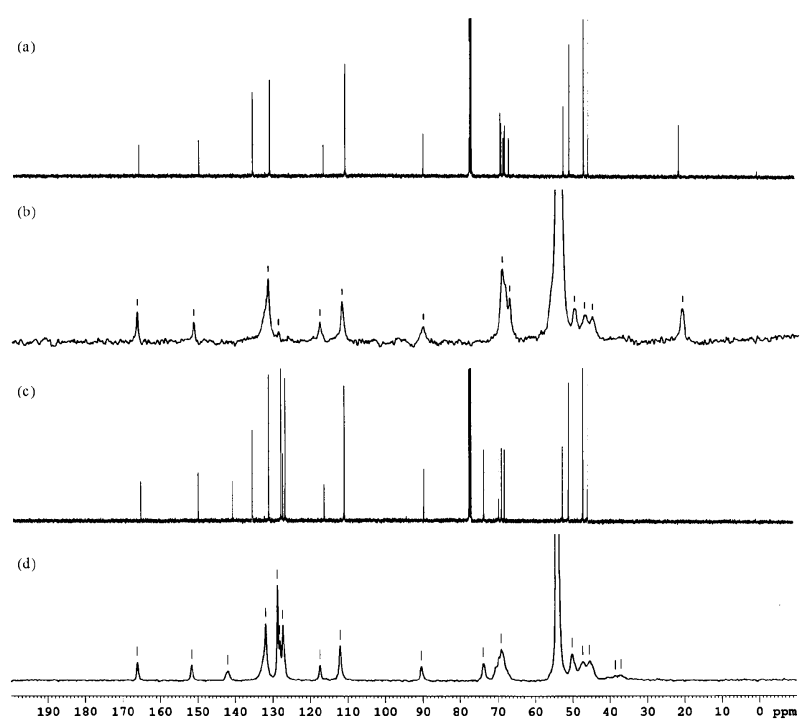

Fig. $1{ }^{13} \mathrm{C}$ NMR spectra (a) 6 a in $\mathrm{CDCl}_{3}$, (b) $7 \mathbf{a}$ in $\mathrm{CD}_{2} \mathrm{Cl}_{2}$ (c) $6 \mathbf{b}$ in $\mathrm{CDCl}_{3}$, (d) $7 \mathbf{b}$ in $\mathrm{CD}_{2} \mathrm{Cl}_{2}$.

The enantiomeric pairs of $\mathbf{6}$ and 7 exhibited mirror-imaged CD profiles in the UV region $(200-360 \mathrm{~nm}) . \dagger$ As shown in Fig. 2a, when $\mathrm{R}$ was $\mathrm{Me}$, both $\mathbf{6 a}$ and $7 \mathbf{a}$ showed single transition in their CD spectra. The relative intensities of the $\mathrm{CD}$ curves for the monomers 6a were even higher than those of 7a. The phenyl

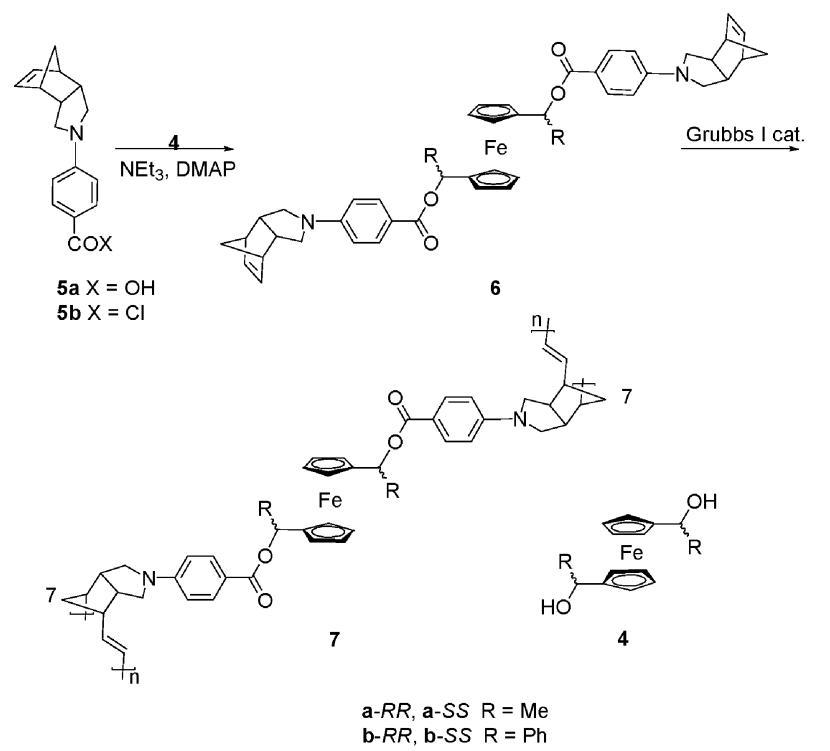

(1)
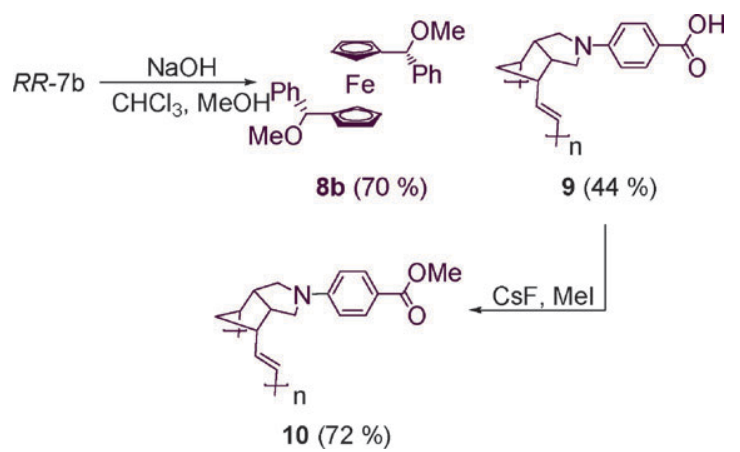
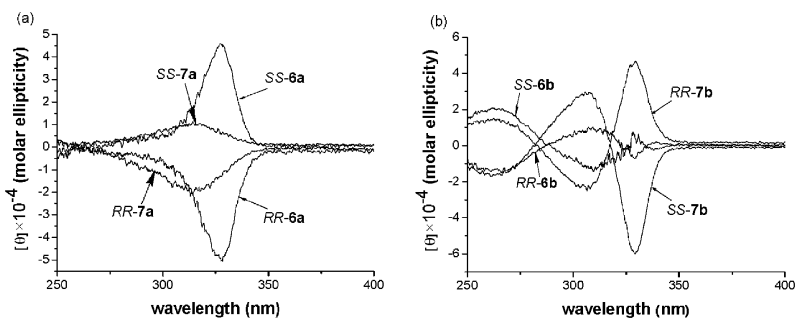

Fig. $2 \mathrm{CD}$ curves of enantiomeric pairs $(R, R$ - and $S, S$-) of (a) 6a (7.5 mg L $\mathrm{mg}^{-1}$ ) and $7 \mathbf{a}\left(15.0 \mathrm{mg} \mathrm{L}^{-1}\right.$, or $2.0 \times 10^{-5} \mathrm{M}$ monomer units), and (b) $6 \mathbf{b}\left(21 \mathrm{mg} \mathrm{L}^{-1}\right)$ and $7 \mathbf{b}\left(21 \mathrm{mg} \mathrm{L}^{-1}\right.$, or $2.4 \times 10^{-5} \mathrm{M}$ monomer units) in $\mathrm{CH}_{2} \mathrm{Cl}_{2}$ at $25^{\circ} \mathrm{C}$.

substituted polymers $\mathbf{7 b}$ exhibited five-fold enhancement of the Cotton effects in comparison with that of the corresponding monomers $6 \mathbf{b}$ (Fig. 2b). Such enhancement may arise from either the helical (or supercoil) structure of $\mathbf{7 b}$ or the induced circular dichroitic property due to interaction between the neighbouring chiral moieties in $\mathbf{7 b}$. The intensities of the CD curves for $S, S-\mathbf{7 b}$ decreased with increasing temperature. $\dagger$ For example, the amplitude of the $\mathrm{CD}$ curve dropped by $70 \%$ when the measurement was recorded at $80{ }^{\circ} \mathrm{C}$, in comparison with that obtained at $0{ }^{\circ} \mathrm{C}$, and the process was irreversible.

A scanning tunneling microscope (STM) was utilised to characterise the chirality and the helical parameters of $\mathbf{7 b}$. Panels a and b of Fig. 3, respectively, display images of single polymers for $R, R-7 \mathbf{b}$ and $S, S-7 \mathbf{b}$. The polymers appeared $9 \sim 11 \mathrm{~nm}$ in length and exhibit $2 \sim 3$ turns with a nominal diameter of $\sim 3 \mathrm{~nm}$. The brighter regimes of the supercoil images were segments intact with the substrate and the darker half turns were closer to the STM tip. The latter had the tunnelling probability decayed more rapidly due to the presence of two tunnelling gaps ${ }^{16}$ of substrate-to-polymer and polymer-to-tip. The depicted coils obtained from simulations (vide infra) illustrate the chiral helicity for $R, R-7 \mathbf{b}$ and $S, S-7 \mathbf{b}$ with $4.5 \sim 4.8 \mathrm{~nm}$ per pitch and a pitch angle of $c a .40^{\circ}$.

It is worthy of note that the features of single polymers $\mathbf{7 b}$ could only be obtained from very diluted samples $(<100 \mathrm{nM})$. Unlike for other ladder-like analogues (e.g. 3), ${ }^{6,7}$ it was difficult to acquire high quality images of individual $\mathbf{7 b}$ even when the dropcast samples were prepared from diluted solutions. The images of single polymers appeared mobile or sometimes translated by the STM tip (e.g. the polymer rotated at the lower half of Fig. $3 \mathrm{~b}$ during the course of imaging). Such imaging difficulty was attributed to the relatively low
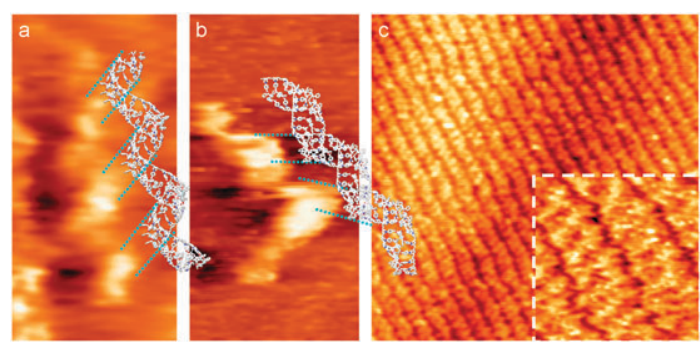

Fig. 3 STM images of (a) $R, R-7 \mathbf{b}$, (b) $S, S-7 \mathbf{b}$, and (c) $R, R-7 \mathbf{b}$ on HOPG (highly oriented pyrolytic graphite). Imaging conditions of

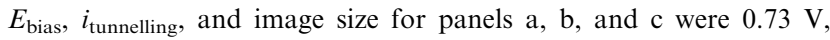
$14 \mathrm{pA}, 10 \times 20 \mathrm{~nm}$, and $0.76 \mathrm{~V}, 11 \mathrm{pA}, 10 \times 20 \mathrm{~nm}$, and $0.68 \mathrm{~V}, 19 \mathrm{pA}$, $80 \times 80 \mathrm{~nm}$ (inset: $12 \times 12 \mathrm{~nm}$ ), respectively. 


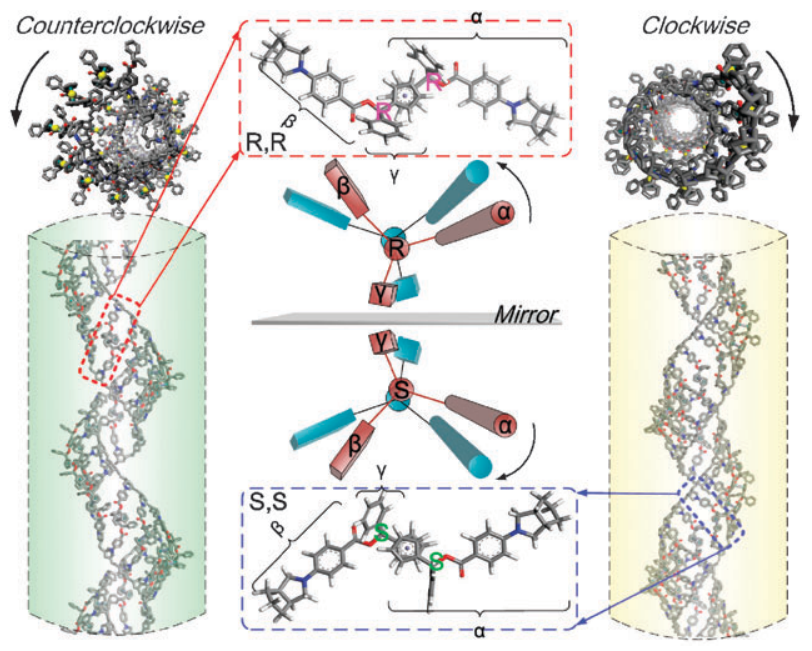

Fig. 4 Schematic representation of molecular modeling and stacking behavior of $R, R-7 \mathbf{b}$ and $S, S-7 \mathbf{b} . \alpha, \beta$, and $\gamma$ represent the ferrocene residue, aminobenzoate fragment, and phenyl substituent, respectively, at the chiral center of $\mathbf{7 b}$.

molecular weights of $\mathbf{7 b}$ and the supercoil nature which resulted in weak adsorbate-substrate interactions.

When the dropcast solution $(0.5 \mu \mathrm{M})$ was subjected to shear alignment, $\dagger$ a close-packed film was assembled on HOPG and the long axis of $R, R-\mathbf{7 b}$ was in parallel with the flow direction (Fig. 3c). It is noteworthy that the end groups in 7 were vinyl and styryl because the Grubbs-I catalyst was employed and the reaction was quenched with ethyl vinyl ether. It seems likely that a strong interaction between these terminal groups of $\mathbf{7 b}$ might take place. Such interaction may develop the extraordinarily long features leading to indiscernible boundaries between neighbouring polymers as depicted in Fig. 3c. The supercoil nature of $\mathbf{7 b}$ was retained in this aggregate. This kind of polymer can be considered as a helical tecton that represents a preorganized chiral nanoscaled building block and allows the facile assembly to form a two-dimensional patterned array through interactions between the terminal groups of the polymers.

Molecular dynamics simulations by a universal force field ${ }^{17}$ on $R, R-7 \mathbf{b}$ and $S, S-7 \mathbf{b}$ of 36 -mers showed that $7 \mathbf{b}$ would adopt supercoil structures (diameter $=3.1 \mathrm{~nm}$, pitch length $=$ $4.9 \mathrm{~nm}$ and 12 monomeric units per pitch) with a trans double bond and isotactic stereochemistry in the backbones. $\dagger$ The relevant structural parameters are closely matched with the STM image of polymers $R, R-7 \mathbf{d}$ and $S, S-7 \mathbf{d}$ (Fig. 3). A slight counter-clockwise oriented stacking of the chiral monomeric units leading to the secondary structures of $R, R-\mathbf{7 d}$ would be relatively more stable than the clockwise one by $3.7 \mathrm{kcal} \mathrm{mol}^{-1}$ per monomer (Fig. 4). In a similar manner, S,S-7d would preferentially have the clockwise supercoil structure.

It is known that the ROMP of norbornene derivatives having fused 5,6-endo- $N$-arylpyrrolidine moiety is highly stereoselective (trans double bonds and homogeneous tacticity), most likely due to interactions between the pending aryl groups. ${ }^{6,7,18}$ Within this context, it seems likely that the presence of chiral substituents on the ferrocene linker as in $\mathbf{6 b}$ may yield the corresponding supercoil polymer (e.g. 7b) which could be the kinetic product. Upon heating, a change of conformation of $\mathbf{7 b}$ may result in decrease in amplitude of the CD curves. Presumably, the barrier for the reverse process to regenerate the original supercoil conformation of $\mathbf{7 b}$ may be unfavourable.

We thank the National Science Council and the National Taiwan University of the Republic of China for support.

\section{Notes and references}

1 (a) J.-M. Lehn, A. Rigault, J. Siegel, J. Harrowfield, B. Chevrier and D. Moras, Proc. Natl. Acad. Sci. U. S. A., 1987, 84, 2565; (b) U. Koert, M. M. Harding and J.-M. Lehn, Nature, 1990, 346, 339; (c) T. Sugimoto, T. Suzuki, S. Shinkai and K. Sada, J. Am. Chem. Soc., 2007, 129, 270.

2 (a) J. Sánchez-Quesada, C. Steel, P. Prados and J. de Mendoza, J. Am. Chem. Soc., 1996, 118, 277; (b) V. Berl, I. Huc, R. G. Khoury, M. J. Krische and J.-M. Lehn, Nature, 2000, 407, 720; (c) Y. Tanaka, H. Katagiri, Y. Furusho and E. Yashima, Angew. Chem., Int. Ed., 2005, 44, 3867.

3 (a) G. J. Gabriel and B. L Iverson, J. Am. Chem. Soc., 2002, 124, 15174; (b) R. Iwaura, F. J. M. Hoeben, M. Masuda, A. P. H. J. Schenning, E. W. Meijer and T. Shimizu, J. Am. Chem. Soc., 2006, 128, 13298.

4 (a) A. Harada, J. Li and M. Kamachi, Nature, 1994, 370, 126 (b) A. P. Bisson and C. A. Hunter, Chem. Commun., 1996, 1723.

5 (a) S. Nagahama and A. Matsumoto, J. Am. Chem. Soc., 2001, 123, 12176; (b) T. E. O. Screen, J. R. G. Thorne, R. G. Denning, D. G. Bucknall and H. L. Anderson, J. Am. Chem. Soc., 2002, 124, 9712; (c) H. Tang, J. Sun, J. Jiang, X. Zhou, T. Hu, P. Xie and R. Zhang, J. Am. Chem. Soc., 2002, 124, 10482.

6 N.-T. Lin, S.-Y. Lin, S.-L. Lee, C.-h. Chen, C.-H. Hsu, L.-P. Hwang, Z.-Y. Xie, C.-H. Chen, S.-L. Huang and T.-Y. Luh, Angew. Chem., Int. Ed., 2007, 46, 4481.

7 H.-C. Yang, S.-Y. Lin, H.-c. Yang, C.-L. Lin, L. Tsai, S.-L. Huang, I.-W. P. Chen, C.-h. Chen, B.-Y. Jin and T.-Y. Luh, Angew. Chem., Int. Ed., 2006, 45, 726.

8 T. Maeda, Y. Furusho, S.-I. Sakurai, J. Kumaki, K. Okoshi and E. Yashima, J. Am. Chem. Soc., 2008, 130, 7938.

9 (a) M. M. Green, N. C. Peterson, T. Sato, A. Teramoto, C. Robert and S. Lifson, Science, 1995, 268, 1860; (b) F. Takei, H. Hayashi, K. Onitsuka, N. Kobayashi and S. Takahashi, Angew. Chem., Int Ed., 2001, 40, 4092; (c) A. Tanatani, T. S. Hughes and J. S. Moore, Angew. Chem., Int. Ed., 2002, 41, 325; (d) C. Dolain, H. Jiang, J.-M. Leger, P. Guionneau and I. Huc, J. Am. Chem. Soc., 2005, 127, 12943; (e) A. J. Wilson, M. Masuda, R. P. Sijbesma and E. W. Meijer, Angew. Chem., Int. Ed., 2005, 44, 2275; ( $f$ ) A. Lohr, M. Lysetska and F. Würthner, Angew. Chem., Int. Ed., 2005, 44 5071; $(g)$ H. Onouchi, T. Miyagawa, K. Morino and E. Yashima, Angew. Chem., Int. Ed., 2006, 45, 2381; (h) D. Pijper and B. L. Feringa, Angew. Chem., Int. Ed., 2007, 46, 3693.

10 (a) P. Schwab, R. H. Grubbs and J. W. Ziller, J. Am. Chem. Soc., 1996, 118, 100; (b) J. G. Hamilton, in Handbook of Metathesis, ed. R. H. Grubbs, Wiley-VCH, Weinheim, 2003, vol. 3, pp. 143-179.

11 C.-L. Lin, H.-C. Yang, N.-T. Lin, I.-J. Hsu, Y. Wang and T.-Y. Luh, Chem. Commun., 2008, 4484.

12 For a recent review, see: E. Yashima, K. Maeda and Y. Furusho, Acc. Chem. Res., 2008, 41, 1166.

13 Y.-Y. Lai, N.-T. Lin, Y.-H. Liu, Y. Wang and T.-Y. Luh, Tetrahedron, 2007, 63, 6051.

14 L. Schwink and P. Knochel, Chem.-Eur. J., 1998, 4, 950.

15 T. Sato, J. Otera and H. Nozaki, J. Org. Chem., 1992, 57, 2166.

16 P. Samori, K. Fechtenkotter, F. Jackel, T. Bohme, K. Müllen and J. P. Rabe, J. Am. Chem. Soc., 2001, 123, 11462.

17 (a) D. Frenkel and B. Smit, Understanding Molecular Simulation: from Algorithms to Applications, Academic Press, 1996; (b) A. R. Leach, Molecular Modeling. Principles and Applications, Longman, 1997; (c) A. K. Rappé, C. J. Casewit, K. S. Colwell, W. A. Goddard, III and W. M. Skiff, J. Am. Chem. Soc., 1992, 114, 10024.

18 (a) W.-Y. Lin, H.-W. Wang, Z.-C. Liu, J. Xu, C.-W. Chen, Y.-C. Yang, S.-L. Huang, H.-C. Yang and T.-Y. Luh, Chem.Asian J., 2007, 2, 764; (b) T.-Y. Luh, H.-C. Yang, N.-T. Lin, S.-Y. Lin, S.-L. Lee and C.-h. Chen, Pure Appl. Chem., 2008, 80, 819. 